\title{
Impact of skeletal muscle mass in patients with recurrent gastric cancer
}

\author{
Tomoyuki Matsunaga ${ }^{1 *} \mathbb{D}$, Hiroaki Satio ${ }^{2}$, Wataru Miyauchi', Yuji Shishido ${ }^{1}$, Kozo Miyatani ${ }^{1}$, Yuki Murakami ${ }^{1}$, \\ Takehiko Hanaki', Kyoichi Kihara', Manabu Yamamoto', Naruo Tokuyasu', Shuichi Takano', Teruhisa Sakamoto', \\ Toshimichi Hasegawa' and Yoshiyuki Fujiwara'
}

\begin{abstract}
Background: We retrospectively examined the relationship among skeletal muscle mass index (SMI), prognosis, and chemotherapy side effects in patients with recurrent gastric cancer (RGC).

Methods: Sixty-seven patients who developed recurrence after undergoing curative gastrectomy for gastric cancer at Tottori University Hospital and received palliative chemotherapy were included in this study. Pretreatment computed tomography was performed to measure the skeletal muscle mass (SMM) and cross-sectional SMM at the third lumbar vertebra. We focused on haematologic toxicity (neutropenia, thrombocytopenia, and anaemia), febrile neutropenia, and gastrointestinal toxicity (diarrhoea, vomiting, and stomatitis) as the side effects of chemotherapy.

Results: Median SMIs for males and females (43.9 and $34.7 \mathrm{~cm}^{2} / \mathrm{m}^{2}$, respectively) were used as cutoff values. The patients were classified into high (SMI High $; n=34)$ and low SMI groups (SML $\left.{ }^{\text {Low }} ; n=33\right)$. The $\mathrm{SMI}^{\text {Low }}$ group included more patients treated with monotherapy $(P=0.016)$ compared with the SMI ${ }^{\text {High }}$ group, had a significantly lower number of chemotherapy lines $(P=0.049)$, and had a significantly higher incidence of grade 3 or 4 side effects $(P=$ 0.010 ). The median survival rate was significantly higher in the SMI ${ }^{\text {High }}$ group (17.8 vs 15.8 months; $P=0.034$ ). In the univariate analysis, body mass index, SMl, histological type, and prognostic nutritional index were identified as prognostic indicators. The multivariate analysis identified SMI $(P=0.037)$ and histological type $(P=0.028)$ as independent prognostic factors.
\end{abstract}

Conclusion: The incidence of grade 3 or 4 side effects was significantly higher in patients with SMI ${ }^{\text {Low }}$ RGC. SMI was a useful prognostic marker of RGC.

Keywords: Gastric cancer, Chemotherapy, Skeletal muscle mass

\section{Introduction}

Gastric cancer remains the fourth most common cancer and the second leading cause of cancer-related death worldwide [1, 2]. Gastrectomy is the main treatment strategy for gastric cancer. However, patients with advanced gastric cancer often experience recurrence [3, 4].

\footnotetext{
* Correspondence: matut0m0@tottori-u.ac.jp

'Division of Gastrointestinal and Pediatric Surgery, Department of Surgery, School of Medicine, Tottori University Faculty of Medicine, 36-1 Nishi-cho, Yonago 683-8504, Japan

Full list of author information is available at the end of the article
}

Chemotherapy is the main treatment for recurrent gastric cancer (RGC). Despite the improvements in prognosis as well as survival outcomes in patients with RGC, the overall outcome remains poor $[5,6]$.

Sarcopenia is characterised by a loss of skeletal muscle mass (SMM) and has been widely reported to impair physical performance and survival in the elderly [7, 8]. The relationship between sarcopenia and prognosis has been reported in various cancers, including gastric cancer [9-17]. In patients with cancer, sarcopenia is more likely to develop due to increased protein catabolism,

(c) The Author(s). 2021 Open Access This article is licensed under a Creative Commons Attribution 4.0 International License, which permits use, sharing, adaptation, distribution and reproduction in any medium or format, as long as you give appropriate credit to the original author(s) and the source, provide a link to the Creative Commons licence, and indicate if changes were made. The images or other third party material in this article are included in the article's Creative Commons licence, unless indicated otherwise in a credit line to the material. If material is not included in the article's Creative Commons licence and your intended use is not permitted by statutory regulation or exceeds the permitted use, you will need to obtain permission directly from the copyright holder. To view a copy of this licence, visit http://creativecommons.org/licenses/by/4.0/. The Creative Commons Public Domain Dedication waiver (http://creativecommons.org/publicdomain/zero/1.0/) applies to the data made available in this article, unless otherwise stated in a credit line to the data. 
inflammatory reactions, metabolic abnormalities, and poor oral intake. Sarcopenia may be associated with cancer cachexia [18]. Cancer cachexia disturbs the regenerative ability of skeletal muscle [19]. Patients with advanced gastric cancer often receive perioperative chemotherapy and the side effects of chemotherapy can cause loss of SMM. In addition, patients experience weight loss after gastrectomy because of poor dietary intake, which leads to various postoperative disorders and SMM loss [20, 21].

At the time of recurrence after gastrectomy, treatment options are limited to chemotherapy or best supportive care, and chemotherapy is administered despite the decrease in SMM. Sarcopenia is reported to possibly influence the pharmacokinetics of chemotherapy, which could be associated with the adverse effects of chemotherapy in several cancers [22]. However, there are few reports on SMM and chemotherapy side effects in patients with RGC. Moreover, there are few reports on SMM and RGC prognosis at the time of recurrence.

In this study, we retrospectively examined the relationship among skeletal muscle index (SMI), prognosis, and side effects of chemotherapy in patients with RGC after undergoing gastrectomy.

\section{Patients and methods \\ Patients}

Between January 2008 and December 2019, 605 patients were pathologically diagnosed with gastric cancer and had undergone curative gastrectomy at Tottori University Hospital. Gastrectomy was performed with D2 lymph node dissection for advanced cancer and D1+ lymph node dissection for early gastric cancer. Patients with stage II or III gastric cancer underwent adjuvant chemotherapy according to the Japanese gastric cancer treatment guidelines [23]. Sixty-seven patients developed recurrence, received palliative chemotherapy, and were included in this study. All the patients received first-line chemotherapy 4 weeks after a computed tomography (CT) scan. Clinicopathological findings were determined according to the Japanese gastric cancer treatment guidelines [23]. Clinical data, including age, sex, histology, history of gastrectomy, and metastatic site at the time of recurrence, were collected from electronic medical records. The patients were followed up every 3 months to check for recurrence by performing blood tests, including those for tumour markers, and by physical examination after the operation. Moreover, CT was performed at least every 6 months after the operation. Recurrence patterns and causes of death were examined from clinical records, CT, and positron emission tomography-CT. A family inquiry was conducted for patients who were difficult to follow up.

\section{Definition of SMI}

Pretreatment CT was performed to measure SMM and the SYNAPSE VINCENT system was used to measure the cross-sectional SMM at the level of the third lumbar vertebra (L3) [24]. The areas covered by SMM were calculated from pixels in the density range of -29 to +150 Hounsfield Units [25], which includes muscle and intraabdominal organs but excludes bone and fat. The L3 region comprises the psoas, paraspinal, and abdominal wall muscles (Fig. 1). The skeletal muscle area in a single abdominal image is proportional to the whole-body muscle mass [26], and SMI is defined as the muscle area normalised by the square of the height $\left(\mathrm{m}^{2}\right)$ [27].

\section{Details of first-line chemotherapy}

The standard first-line palliative systemic chemotherapy was a fluoropyrimidine-, taxane-, or irinotecan-based regimen that was administered in accordance with the gastric cancer treatment guidelines for each decade [23, 28]. At the physician's discretion, a single agent was used in patients with PS 2, those older than 80 years, or those who refused combined chemotherapy. In this study, monotherapy was administered in 23 patients and combination chemotherapy was administered in 44 patients. The monotherapy regimens included the following: (i) CPT-11 $(n=11)$, (ii) S-1 $(n=8)$, and (iii) paclitaxel $(n=4)$. The combination chemotherapy regimens were as follows: (iv) combined paclitaxel + ramucirumab $(n=11)$, (v) combined S-1 + cisplatin $(n=8)$, (vi) combined S-1 + docetaxel $(n=7)$, (vii) combined capecitabine + oxaliplatin $(n$ $=5)$, (viii) combined S- $1+$ oxaliplatin $(n=4)$, (ix) combined capecitabine + cisplatin $(n=3),(x)$ combined S- $1+$ paclitaxel + intraperitoneally infused paclitaxel $(n=3),(x i)$ combined CPT- $11+$ cisplatin $(n=2)$, and (xii) combined capecitabine + trastuzumab $(n=1)$. Of the 67 patients who underwent chemotherapy for RGC, 55 patients $(82.1 \%)$ received second-line chemotherapy.

\section{Definition of side effect}

The side effects of chemotherapy were graded according to the National Cancer Institute Common Toxicity Criteria, version 4.0 [29]. In this study, we examined the side effects observed during cycles 1-2 of first-line chemotherapy. If multiple side effects were observed, the higher grade was used in the present study. We specifically focused on haematologic toxicity (neutropenia, thrombocytopenia, and anaemia), febrile neutropenia (FN), and gastrointestinal toxicity (diarrhoea, vomiting, and stomatitis).

\section{Statistical analysis}

Continuous variables were expressed as means \pm standard deviation and compared using the Mann-Whitney $\mathrm{U}$ test. The $\chi^{2}$ test or Fisher's exact test was used to 


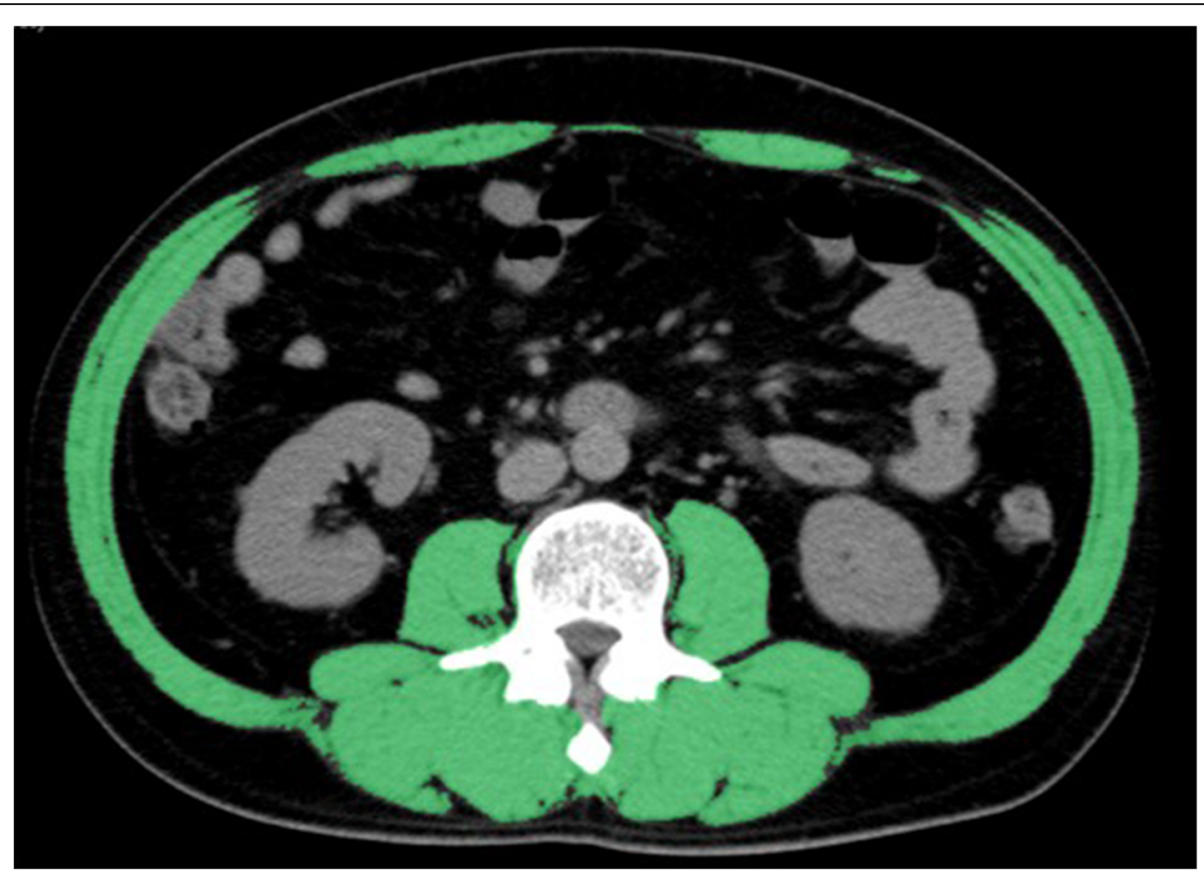

Fig. 1 Measurement of SMM in RGC patients. Axial computed tomography slice of the third lumbar vertebra (L3). Green areas indicate skeletal muscle mass. Abbreviations: RGC, recurrent gastric cancer; SMM, skeletal muscle mass

compare categorical variables. Survival curves were calculated using the Kaplan-Meier method, and differences between survival curves were examined using the logrank test. The univariate and multivariate analyses of the prognostic factors of overall survival (OS) were performed using Cox's proportional hazards model. $P<0.05$ was considered significant, and all statistical analyses were performed using SPSS software (SPSS for Windows version 24; IBM Corp., Armonk, NY, USA).

\section{Results}

\section{Patient characteristics}

The average SMI was $42.3 \mathrm{~cm}^{2} / \mathrm{m}^{2}$, and the median SMI for each sex (male, $43.9 \mathrm{~cm}^{2} / \mathrm{m}^{2}$; female, $34.7 \mathrm{~cm}^{2} / \mathrm{m}^{2}$ ) was used as cutoff values to classify patients into a high SMI group (SMI High group; $n=34$ ) and a low SMI group (SMI ${ }^{\text {Low }}$ group; $n=33$ ). The patients' clinicopathological characteristics are shown in Table 1. Overall, there were 55 male and 12 female patients, and their average age was 67.6 years. The Eastern Cooperative Oncology Group performance status (ECOG PS) of 59 and 8 patients was $0-1$ and 2, respectively. Details of the initial surgery showed that 8 patients had stage I disease, 20 had stage II disease, and 39 had stage III disease. The most common metastatic site was the peritoneum, followed by the haematogenous site and lymph nodes. Regarding histology, 36 patients had a differentiatedtype carcinoma and 31 had an undifferentiated-type carcinoma. The relationships between SMI and clinicopathological variables of the patients are shown in Table 1, and the relationships between SMI and characteristics of initial surgery of the patients are shown in Table 2. Body mass index (BMI) was significantly higher in patients in the $\mathrm{SMI}^{\mathrm{High}}$ group than in the SMI ${ }^{\mathrm{Low}}$ group $(P<0.001)$. The number of chemotherapy lines was significantly lower in the SMI ${ }^{\text {Low }}$ group than in the $\mathrm{SMI}^{\text {High }}$ group $(P=0.049)$. No significant differences were observed with respect to age, sex, ECOG PS, adjuvant chemotherapy, prognostic nutritional index (PNI), metastatic site, tumour size, tumour invasion depth, lymph node metastasis, histological type, lymphatic invasion, venous invasion, pathological stage, tumour size, and gastrectomy type.

\section{Details of first-line chemotherapy and side effects}

The details of SMI and first-line chemotherapy are presented in Table 3. The SMI ${ }^{\text {Low }}$ group included more patients treated with monotherapy compared with the SMI ${ }^{\text {High }}$ group $(P=0.016)$. The details of SMI and side effects are presented in Table 4. The incidence of all side effects of grade 3 or 4 was significantly higher in the $\mathrm{SMI}^{\mathrm{Low}}$ group than in the $\mathrm{SMI}^{\mathrm{High}}$ group $(P=0.010)$. The incidence of grade 3 or 4 gastrointestinal toxicity was significantly higher in the SMI ${ }^{\text {Low }}$ group than in the $\mathrm{SMI}^{\mathrm{High}}$ group $(P=0.018)$. No significant differences were observed in terms of neutropenia, anaemia, thrombocytopenia, and FN. In patients receiving monotherapy, the incidence of grade 3 or 4 gastrointestinal 
Table 1 Clinicopathological characteristics of SMI ${ }^{\text {High }}$ and SMI ${ }^{\text {Low }}$ RGC patients

\begin{tabular}{|c|c|c|c|c|}
\hline & All patients $(n=67)$ & $\mathrm{SMI}^{\mathrm{High}}(n=34)$ & $\mathrm{SML}^{\text {Low }}(n=33)$ & $p$ value \\
\hline Age (years) & $67.6 \pm 9.9$ & $66.7 \pm 9.7$ & $68.6 \pm 10.1$ & 0.376 \\
\hline Sex & & & & 0.954 \\
\hline Male & $55(82.1)$ & $28(82.4)$ & $27(81.8)$ & \\
\hline Female & $12(17.9)$ & $6(17.6)$ & $6(18.2)$ & \\
\hline ECOG PS $(0 / 1 / 2)$ & & & & 0.121 \\
\hline 0,1 & $59(88.1)$ & $32(94.1)$ & $27(81.8)$ & \\
\hline 2 & $8(11.9)$ & $2(5.9)$ & $6(18.2)$ & \\
\hline $\mathrm{BMI}$ & $19.4 \pm 3.0$ & $20.9 \pm 3.0$ & $17.9 \pm 2.0$ & $<0.001$ \\
\hline SMI & $42.3 \pm 7.7$ & $47.4 \pm 6.5$ & $37.1 \pm 4.6$ & $<0.001$ \\
\hline Adjuvant chemotherapy & & & & 0.140 \\
\hline Present & $50(74.6)$ & $28(82.4)$ & $22(66.7)$ & \\
\hline Absent & $17(25.4)$ & $6(17.6)$ & $11(33.3)$ & \\
\hline \multicolumn{5}{|l|}{ Number of chemotherapy line } \\
\hline One & $12(17.9)$ & $3(8.8)$ & $9(27.3)$ & 0.049 \\
\hline Two and more & $55(82.1)$ & $31(91.2)$ & $24(72.7)$ & \\
\hline $\mathrm{PNI}$ & $45.9 \pm 7.7$ & $47.0 \pm 5.7$ & $44.7 \pm 7.7$ & 0.241 \\
\hline Peritoneum metastasis & & & & 0.715 \\
\hline Positive & $33(49.3)$ & $16(47.1)$ & $17(51.5)$ & \\
\hline Negative & $34(50.7)$ & $18(52.9)$ & $16(48.5)$ & \\
\hline Haematogenous metastasis & & & & 0.545 \\
\hline Positive & $22(32.8)$ & $10(29.4)$ & $12(36.4)$ & \\
\hline Negative & $45(67.2)$ & $24(70.6)$ & $21(63.6)$ & \\
\hline Lymph node metastasis & & & & 0.856 \\
\hline Positive & $21(31.3)$ & $11(32.4)$ & $10(30.3)$ & \\
\hline Negative & $46(68.7)$ & $23(67.6)$ & $23(69.7)$ & \\
\hline
\end{tabular}

Data are presented as the mean \pm standard deviation or number (percentage) of patients

$B M I$ body mass index, $P N I$ the prognostic nutritional index, $R G C$ recurrent gastric cancer, $S M I$ skeletal muscle mass, $S M I^{\text {High }}$ high skeletal muscle mass, SMI ${ }^{\text {Low }}$ low skeletal muscle mass

toxicity tended to be higher in the SMI ${ }^{\text {Low }}$ group than in the $\mathrm{SMI}^{\mathrm{High}}$ group $(P=0.106$, Table 5$)$. In patients receiving combined chemotherapy, the incidence of grade 3 or 4 gastrointestinal toxicity was significantly higher in the $\mathrm{SMI}^{\mathrm{Low}}$ group than in the $\mathrm{SMI}^{\mathrm{High}}$ group $(P=0.011$, Table 5). The median survival rate was significantly higher in the $\mathrm{SMI}^{\text {High }}$ group than in the $\mathrm{SMI}^{\mathrm{Low}}$ group (17.8 vs 15.8 months; $P=0.034$, Fig. 2 ).

Univariate and multivariate analyses of patients with RGC We performed a univariate analysis of the clinicopathological factors considered prognostic for OS in patients with RGC. In the univariate analysis, BMI, SMI, histological type, and PNI were identified as prognostic indicators (Table 6). In the multivariate analysis, we included significant parameters that were identified in the univariate analysis. The multivariate analysis revealed that SMI and histological type were independent prognostic factors (Table 6).

\section{Discussion}

In this study, the SMI ${ }^{\text {Low }}$ group had significantly more grade 3 or 4 side effects than the $\mathrm{SMI}^{\text {High }}$ group, even though the SMI ${ }^{\text {Low }}$ group underwent less monotherapy than the SMI ${ }^{\text {High }}$ group. The SMI ${ }^{\text {Low }}$ group had a significantly worse prognosis and significantly less conversion to second-line chemotherapy than the SMI ${ }^{\text {High }}$ group.

Moreover, SMI ${ }^{\text {Low }}$ in patients with RGC was associated with grade 3 or 4 gastrointestinal side effects; this result was similar to that of a previous report by Carla et al. [30], where the side effects in 55 patients with metastatic breast cancer receiving capecitabine treatment were retrospectively reviewed. The cross-sectional skeletal muscle area at the third lumbar vertebra was measured using CT, and sarcopenia was defined using a previously published cutoff point. Consequently, sarcopenia was found to be associated with grade 3-4 diarrhoea and stomatitis. Shachar et al. also reported that they retrospectively reviewed side effects in 40 patients 
Table 2 Clinicopathological characteristics at initial surgery in SMI ${ }^{\text {High }}$ and SMI ${ }^{\text {Low }}$ RGC patients

\begin{tabular}{|c|c|c|c|c|}
\hline & All patients $(n=67)$ & $\mathrm{SMI}^{\mathrm{High}}(n=34)$ & $\mathrm{SMI}^{\text {Low }}(n=33)$ & $p$ value \\
\hline Depth of tumour invasion & & & & 0.846 \\
\hline $\mathrm{T} 1$ & $10(14.9)$ & $4(11.8)$ & $6(18.2)$ & \\
\hline $\mathrm{T} 2$ & $8(11.9)$ & $4(11.8)$ & $4(12.1)$ & \\
\hline T3 & $28(41.8)$ & $14(41.1)$ & $14(42.4)$ & \\
\hline T4 & $21(31.4)$ & $12(35.3)$ & $9(27.3)$ & \\
\hline Lymph node metastasis & & & & 0.461 \\
\hline Positive & $57(85.1)$ & $30(88.2)$ & $27(81.8)$ & \\
\hline Negative & $10(14.9)$ & $4(11.8)$ & $6(18.2)$ & \\
\hline Histologic type & & & & 0.895 \\
\hline Differentiated & $36(53.7)$ & $18(52.9)$ & $18(54.5)$ & \\
\hline Undifferentiated & $31(46.3)$ & $16(47.1)$ & $15(45.5)$ & \\
\hline Lymphatic invasion & & & & 0.537 \\
\hline Positive & $64(95.5)$ & $33(97.1)$ & $31(93.9)$ & \\
\hline Negative & $3(4.5)$ & $1(2.9)$ & $2(6.1)$ & \\
\hline Venous invasion & & & & 0.371 \\
\hline Positive & $61(91.0)$ & $32(94.1)$ & $29(87.9)$ & \\
\hline Negative & $6(9.0)$ & $2(5.9)$ & $4(12.1)$ & \\
\hline Stage of disease & & & & 0.281 \\
\hline 1 & $8(11.9)$ & $3(8.8)$ & $5(15.2)$ & \\
\hline$\|$ & $20(29.9)$ & $8(23.5)$ & $12(36.4)$ & \\
\hline III & $39(58.2)$ & $23(67.7)$ & $16(48.4)$ & \\
\hline Tumour size (mm) & $10.0 \pm 2.0$ & $12.7 \pm 25.8$ & $7.3 \pm 11.0$ & 0.072 \\
\hline Type of gastrectomy & & & & 0.478 \\
\hline Distal & $30(44.8)$ & $13(38.2)$ & $17(51.5)$ & \\
\hline Proximal & $6(9.0)$ & $4(11.8)$ & $2(6.1)$ & \\
\hline Total & $31(46.2)$ & $17(50.0)$ & $14(42.4)$ & \\
\hline
\end{tabular}

Data are presented as number (percentage) of patients

$R G C$ recurrent gastric cancer, SMI skeletal muscle mass, $S M I^{\text {High }}$ high skeletal muscle mass, $S M I^{\text {Low }}$ low skeletal muscle mass

Table 3 The detail of first-line chemotherapy between RGC patients with SMI ${ }^{\text {High }}$ and those with SMI ${ }^{\text {Low }}$

\begin{tabular}{|c|c|c|c|}
\hline & $\mathrm{SMI}^{\mathrm{High}}(n=34)$ & SMI $^{\text {Low }}(n=33)$ & $\overline{p \text { value }}$ \\
\hline Monotherapy & 7 (20.6) & $16(48.5)$ & 0.016 \\
\hline CPT-11 & $4(11.8)$ & $7(21.2)$ & \\
\hline S-1 & $1(2.9)$ & $7(21.2)$ & \\
\hline Paclitaxel & $2(5.9)$ & $2(6.1)$ & \\
\hline Combined chemotherapy & $27(79.4)$ & $17(51.5)$ & \\
\hline Paclitaxel + ramucirumab & $6(17.7)$ & $5(15.1)$ & \\
\hline S-1 + docetaxel & $6(17.7)$ & $2(6.1)$ & \\
\hline S-1 + cisplatin & $5(14.7)$ & $2(6.1)$ & \\
\hline Capecitabine + oxaliplatin & $1(2.9)$ & $4(12.1)$ & \\
\hline S-1 + oxaliplatin & $4(11.8)$ & 0 & \\
\hline Capecitabine + cisplatin & $1(2.9)$ & $2(6.1)$ & \\
\hline Combined S-1 + paclitaxel + intraperitoneally infused paclitaxel & $2(5.9)$ & $1(3.0)$ & \\
\hline CPT-11 + cisplatin & $1(2.9)$ & $1(3.0)$ & \\
\hline Capecitabine + trastuzumab & $1(2.9)$ & 0 & \\
\hline
\end{tabular}


Table 4 The detail of side effect between RGC patients with SMI ${ }^{\text {High }}$ and those with SMI ${ }^{\text {Low }}$

\begin{tabular}{|c|c|c|c|}
\hline & $\mathrm{SMI}^{\mathrm{High}}(n=34)$ & $\mathrm{SMI}^{\text {Low }}(n=33)$ & $p$ value \\
\hline All side effect of grade 3 or 4 & & & 0.010 \\
\hline Positive & $11(32.4)$ & $21(63.6)$ & \\
\hline Negative & $23(67.6)$ & $12(36.4)$ & \\
\hline Neutropenia of grade 3 or 4 & & & 0.267 \\
\hline Positive & $10(29.4)$ & $14(42.4)$ & \\
\hline Negative & $24(70.6)$ & 19 (57.6) & \\
\hline Anaemia of grade 3 or 4 & & & 0.975 \\
\hline Positive & $2(5.9)$ & $2(6.1)$ & \\
\hline Negative & $32(94.1)$ & $31(93.9)$ & \\
\hline Thrombocytopenia of grade 3 or 4 & & & 0.968 \\
\hline Positive & $1(2.9)$ & $2(6.1)$ & \\
\hline Negative & $33(97.1)$ & $31(93.9)$ & \\
\hline Gastrointestinal toxicity & & & 0.018 \\
\hline Positive & $2(5.9)$ & $9(27.3)$ & \\
\hline Negative & $32(94.1)$ & $24(72.7)$ & \\
\hline FN & & & 0.215 \\
\hline Positive & $2(5.9)$ & $5(15.2)$ & \\
\hline Negative & $32(94.1)$ & $28(84.8)$ & \\
\hline
\end{tabular}

Data are presented as number (percentage) of patients

$R G C$ recurrent gastric cancer, $S M I$ skeletal muscle mass, $S M I^{\text {High }}$ high skeletal muscle mass, $S M l^{\text {Low }}$ low skeletal muscle mass

with metastatic breast cancer and showed that SMI ${ }^{\text {Low }}$ was associated with grade 3-4 toxicity [31]. Likewise, Tan et al. reported that sarcopenia was associated with dose-limiting toxicity in 89 patients with oesophagogastric cancer undergoing neoadjuvant chemotherapy [32]. Their multivariate analysis revealed that only sarcopenia was an independent risk factor of dose-limiting toxicity. These results show that $\mathrm{SMI}^{\mathrm{Low}}$ is related to the highgrade toxicity of chemotherapy. However, the mechanism associating $\mathrm{SMI}^{\mathrm{Low}}$ and toxicity is unclear. One possible explanation is that changes in body composition are related to alterations in the distribution and clearance of the anticancer agent [32]. 5-FU, a key drug in gastric cancer, is hydrophilic but widely distributed through active transport [33]. This drug undergoes extensive metabolism, primarily through dihydropyrimidine dehydrogenase. Variants of dihydropyrimidine dehydrogenase have been associated with an increased risk of 5-FU toxicity [34]. The clearance of 5-FU is increased in individuals with higher SMM [35]. These findings suggest that decreased clearance of 5-FU due to $\mathrm{SMI}^{\mathrm{Low}}$ may be related to the increased side effects. To the best of our knowledge, this is the first report in which $\mathrm{SMI}^{\mathrm{Low}}$ was associated with grade 3 or 4 side effects in patients with RGC.

Sarcopenia has been shown to negatively impact longterm outcomes of patients with several cancer types [11, $36,37]$. However, only a few studies have investigated the effect of sarcopenia on the prognosis of patients with RGC. Willemieke et al. retrospectively reviewed the prognosis of 88 patients with advanced oesophagogastric cancer treated with standard first-line palliative chemotherapy. They showed that the survival rate was not different between patients with and without sarcopenia in univariate and multivariate analyses. The cutoff in this study was set based on the presence or absence of sarcopenia, which is different from our cutoff, and may have caused the discrepancy. By contrast, Kouzu et al.

Table 5 The side effects of monotherapy and combined therapy between RGC patients in SMI ${ }^{\text {High }}$ and SMI ${ }^{\text {Low }}$ groups

\begin{tabular}{|c|c|c|c|c|c|c|c|}
\hline Monotherapy & $\begin{array}{l}\mathrm{SMI}^{\mathrm{High}} \\
(n=7)\end{array}$ & $\operatorname{SMI}^{\text {Low }}(n=16)$ & $p$ value & Combined chemotherapy & $\mathrm{SMI}^{\mathrm{High}}(n=27)$ & $\mathrm{SMI}^{\text {Low }}(n=17)$ & $p$ value \\
\hline All side effects of grade 3 or 4 & & & 0.106 & All side effects of grade 3 or 4 & & & 0.011 \\
\hline Positive & $1(14.3)$ & $8(50.0)$ & & Positive & $10(37.0)$ & $13(76.5)$ & \\
\hline Negative & $6(85.7)$ & $8(50.0)$ & & Negative & $17(63.0)$ & $4(23.5)$ & \\
\hline
\end{tabular}

Data are presented as number (percentage) of patients

$R G C$ recurrent gastric cancer, $S M I$ skeletal muscle mass, $S M I^{\text {High }}$ high skeletal muscle mass, $S M l^{\text {Low }}$ low skeletal muscle mass 


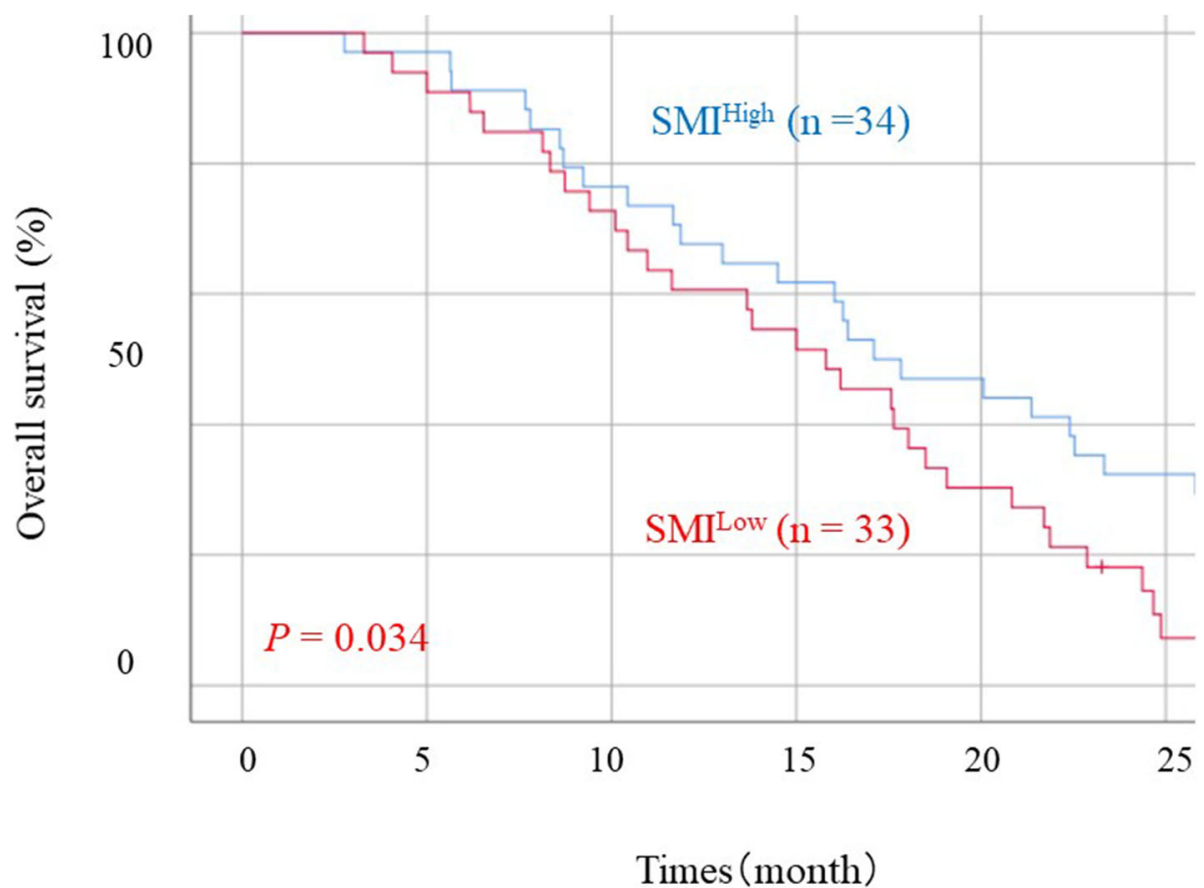

Fig. 2 Overall survival curves according to SMI in patients with RGC. Abbreviations: RGC, recurrent gastric cancer; SMI ${ }^{\text {High }}$, high skeletal muscle mass; SML Low, low skeletal muscle mass

Table 6 Univariate and multivariate analyses of prognostic factors for OS in RGC patients

\begin{tabular}{|c|c|c|c|c|c|c|}
\hline & \multicolumn{3}{|c|}{ Univariate analysis } & \multicolumn{3}{|c|}{ Mutivariate analysis } \\
\hline & Hazard ratio & $95 \% \mathrm{Cl}$ & $P$ value & Hazard ratio & $95 \% \mathrm{Cl}$ & $P$ value \\
\hline Age $(\geqq 75$ vs $<75)$ & 0.966 & $0.557-1.675$ & 0.903 & & & \\
\hline Sex (female vs male) & 1.084 & $0.573-2.052$ & 0.803 & & & \\
\hline ECOG PS (2 vs 0,1$)$ & 1.542 & $0.929-2.560$ & 0.094 & & & \\
\hline $\mathrm{BMI}(<18.5$ vs $\geqq 18.5)$ & 1.859 & $1.101-3.132$ & 0.020 & 1.142 & $0.597-2.184$ & 0.688 \\
\hline SMI (low vs high) & 1.744 & $1.035-2.939$ & 0.037 & 1.938 & $1.041-3.608$ & 0.037 \\
\hline pT $(4$ vs $1,2,3)$ & 1.281 & $0.752-2.181$ & 0.362 & & & \\
\hline $\mathrm{pN}(2,3$ vs 1,2$)$ & 1.310 & $0.775-2.211$ & 0.313 & & & \\
\hline Lymphatic invasion $(2,3$ vs 0,1$)$ & 1.739 & $0.964-3.133$ & 0.066 & & & \\
\hline Venous invasion $(2,3$ vs 0,1$)$ & 1.266 & $0.759-2.110$ & 0.367 & & & \\
\hline Histologic type (undifferentiated vs differentiated) & 2.140 & $1.272-3.601$ & 0.004 & 1.860 & $1.067-3.241$ & 0.028 \\
\hline Type of gastrectomy (proximal/distal vs total) & 0.885 & $0.538-1455$ & 0.629 & & & \\
\hline Adjuvant chemotherapy (present vs absent) & 0.793 & $0.453-1.388$ & 0.417 & & & \\
\hline $\mathrm{PNI}(<44.0$ vs $\geqq 44.0)$ & 1.892 & $1.119-3.198$ & 0.017 & 1.720 & $0.895-3.305$ & 0.104 \\
\hline Peritoneum recurrence (present vs absent) & 1.414 & $0.831-2.405$ & 0.202 & & & \\
\hline Lymph node recurrence (present vs absent) & 0.970 & $0.568-1.657$ & 0.912 & & & \\
\hline Haematogenous metastasis (present vs absent) & 1.000 & $0.606-1.649$ & 0.999 & & & \\
\hline
\end{tabular}

BMI body mass index, ECOG PS Eastern Cooperative Oncology Group performance status, OS overall survival, $P N I$ the prognostic nutritional index, $p N$ pathological lymph node metastasis, $P T$ pathological depth of tumour invasion, $R G C$ recurrent gastric cancer, $S M I$ skeletal muscle mass, SMI ${ }^{\text {High }}$ high skeletal muscle mass, $S M L^{\text {Low }}$ low skeletal muscle mass 
concluded that sarcopenia was a poor prognostic factor after gastric cancer recurrence. They retrospectively reviewed 67 patients who experienced gastric cancer recurrence and found that sarcopenia was an independent negative prognostic factor in a multivariate analysis, which is similar to our result. They calculated the psoas muscle index (PMI) and used a receiver operating characteristic curve to determine the cutoff PMI. These results suggest that $\mathrm{SMI}^{\mathrm{Low}}$ may be associated with prognosis, although there are problems with SMI evaluation and setting of the cutoff values.

The reason for the poor prognosis of patients with $\mathrm{SMI}^{\text {Low }}$ RGC has not been sufficiently elucidated. One potential explanation is that these patients were less likely to receive second-line chemotherapy. The first choice of treatment for patients with metastatic gastric cancer is chemotherapy, and patients need to undergo second- and third-line chemotherapy for further improvement of treatment outcomes [38-40]. In this study, the rate of second-line chemotherapy was significantly lower in the $\mathrm{SMI}^{\mathrm{Low}}$ group than in the $\mathrm{SMI}^{\mathrm{High}}$ group, which might have led to the poor prognosis in the SMILow group.

The standard first-line palliative systemic chemotherapy is a combined regimen in accordance with the Japanese gastric cancer treatment guidelines [41]. However, $\mathrm{SMI}^{\mathrm{Low}}$ in patients with RGC was associated with grade 3 or 4 side effects and the rate of second-line chemotherapy was significantly lower in the SMI ${ }^{\mathrm{Low}}$ group than in the $\mathrm{SMI}^{\mathrm{High}}$ group. Gastrectomy causes not only weight loss but also SMM loss [21]. Preoperative nutritional and exercise interventions for gastric cancer may be useful in improving postoperative outcomes [42]. However, few reports have focused on the effects of postoperative nutritional or rehabilitative interventions on the postoperative development of sarcopenia and outcomes [43]. Postoperative nutritional management and regular exercise may be important for the maintenance of SMM and nutritional status at the time of gastric cancer recurrence in patients at a high risk of recurrence after gastrectomy. In addition, nutritional and rehabilitative interventions during chemotherapy to maintain SMM and nutritional status may be associated with decreased side effects and an increased rate of second-line chemotherapy administration.

This study has several limitations. First, we conducted this study in a single institution, and the number of patients who experienced postoperative recurrence was relatively small. Second, the optimal cutoff SMI value has not been determined in patients with RGC. Because postoperative patients with gastric cancer often have lower dietary intake, body weight, and SMM, and reports of SMM in patients with RGC are few, hence, the SMI median value of all patients was used as the cutoff value in this study. Third, the first-line chemotherapy was not unified. Although this was a long-term study and the guidelines changed over time, chemotherapy was administered in accordance with the guidelines at that time. Therefore, well-designed, randomised, prospective studies with larger populations are needed to confirm these findings.

In conclusion, patients with SMI ${ }^{\text {Low }}$ RGC had significantly more grade 3 or 4 side effects than those with $\mathrm{SMI}^{\mathrm{High}}$, and SMI was a useful prognostic marker of RGC. In patients with advanced gastric cancer after gastrectomy with a high risk of recurrence, interventions to prevent the loss of SMM, such as nutritional therapy and regular exercise, might be needed to improve the prognosis in patients with RGC.

\section{Abbreviations \\ BMI: Body mass index; ECOG PS: Eastern Cooperative Oncology Group performance status; FN: Febrile neutropenia; OS: Overall survival; PNI: The prognostic nutritional index; pN: Pathological lymph node metastasis; pStage: Pathological stage; pT: Pathological depth of tumour invasion; RGC: Recurrent gastric cancer; SMI: Skeletal muscle mass index; SMIligh: High

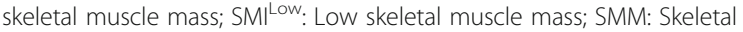 muscle mass}

\section{Acknowledgements}

We thank Enago Group for editing a draft of this manuscript.

\section{Authors' contributions}

Study conception: TM; study design: TM; data acquisition: WM, YS, KM, YM, $\mathrm{TH}$, and KK; quality control of data and algorithms: MY and NT; data analysis and interpretation: ST, TS, and TH; statistical analysis: TM; manuscript preparation: TM; manuscript editing: HS; manuscript review: YF; final approval of the article: all authors.

\section{Funding}

The authors have no financial support to declare.

\section{Availability of data and materials}

The datasets used and analysed during the current study are available from the corresponding author on reasonable request.

\section{Declarations}

Ethics approval and consent to participate

All procedures performed in this study involving human participants were in accordance with the ethical standards of the institutional review board of ethics committee and national research committee with the 1964 Helsinki Declaration and its later amendments. The institutional review board of our institution approved the study (Tottori University, number 18A154). The informed consent requirement was waived.

\section{Consent for publication}

Not applicable.

\section{Competing interests}

The authors declare that they have no competing interests.

\section{Author details}

'Division of Gastrointestinal and Pediatric Surgery, Department of Surgery, School of Medicine, Tottori University Faculty of Medicine, 36-1 Nishi-cho, Yonago 683-8504, Japan. ${ }^{2}$ Department of Surgery, Japanese Red Cross Tottori Hospital, 117 Shotoku-cho, Tottori 680-8517, Japan. 
Received: 18 March 2021 Accepted: 2 June 2021

Published online: 11 June 2021

\section{References}

1. Bray F, Jemal A, Grey N, Ferlay J, Forman D. Global cancer transitions according to the Human Development Index (2008-2030): a populationbased study. Lancet Oncol. 2012;13(8):790-801. https://doi.org/10.1016/S14 70-2045(12)70211-5.

2. Ferlay J, Soerjomataram I, Dikshit R, Eser S, Mathers C, Rebelo M, et al. Cancer incidence and mortality worldwide: sources, methods and major patterns in GLOBOCAN 2012. Int J Cancer. 2015;136(5):E359-86. https://doi. org/10.1002/ijc.29210.

3. Moon YW, Jeung HC, Rha SY, Yoo NC, Roh JK, Noh SH, et al. Changing patterns of prognosticators during 15-year follow-up of advanced gastric cancer after radical gastrectomy and adjuvant chemotherapy: a 15-year follow-up study at a single Korean institute. Ann Surg Oncol. 2007;14(10): 2730-7. https://doi.org/10.1245/s10434-007-9479-4.

4. Zou ZH, Zhao LY, Mou TY, Hu YF, Yu J, Liu H, et al. Laparoscopic vs open D2 gastrectomy for locally advanced gastric cancer: a meta-analysis. World J Gastroenterol. 2014;20(44):16750-64. https://doi.org/10.3748/wjg.v20.i44.1 6750.

5. Koizumi W, Narahara H, Hara T, Takagane A, Akiya T, Takagi M, et al. S-1 plus cisplatin versus S-1 alone for first-line treatment of advanced gastric cancer (SPIRITS trial): a phase III trial. Lancet Oncol. 2008;9(3):215-21. https://doi. org/10.1016/S1470-2045(08)70035-4.

6. Fuchs CS, Tomasek J, Yong CJ, Dumitru F, Passalacqua R, Goswami C, et al. Ramucirumab monotherapy for previously treated advanced gastric or gastro-oesophageal junction adenocarcinoma (REGARD): an international, randomised, multicentre, placebo-controlled, phase 3 trial. Lancet. 2014; 383(9911):31-9. https://doi.org/10.1016/S0140-6736(13)61719-5.

7. Janssen I, Heymsfield SB, Ross R. Low relative skeletal muscle mass (sarcopenia) in older persons is associated with functional impairment and physical disability. J Am Geriatr Soc. 2002;50(5):889-96. https://doi.org/10.1 046/j.1532-5415.2002.50216.x.

8. Cruz-Jentoft AJ, Baeyens JP, Bauer JM, Boirie Y, Cederholm T, Landi F, et al. Sarcopenia: European consensus on definition and diagnosis: report of the European Working Group on Sarcopenia in Older People. Age Ageing. 2010; 39(4):412-23. https://doi.org/10.1093/ageing/afq034.

9. Kamarajah SK, Bundred J, Tan BHL. Body composition assessment and sarcopenia in patients with gastric cancer: a systematic review and metaanalysis. Gastric Cancer. 2019;22(1):10-22. https://doi.org/10.1007/s10120-01 8-0882-2.

10. Ubachs J, Ziemons J, Minis-Rutten IJG, Kruitwagen R, Kleijnen J, Lambrechts S, et al. Sarcopenia and ovarian cancer survival: a systematic review and meta-analysis. J Cachexia Sarcopenia Muscle. 2019;10(6):1165-74. https://doi. org/10.1002/jcsm.12468.

11. Yang M, Shen $Y$, Tan L, Li W. Prognostic value of sarcopenia in lung cancer: a systematic review and meta-analysis. Chest. 2019;156(1):101-11. https:// doi.org/10.1016/j.chest.2019.04.115.

12. Deng HY, Zha $P$, Peng $L$, Hou L, Huang KL, Li XY. Preoperative sarcopenia is a predictor of poor prognosis of esophageal cancer after esophagectomy: a comprehensive systematic review and meta-analysis. Dis Esophagus. 2019; 32(3). https://doi.org/10.1093/dote/doy115.

13. Qian Y, Liu H, Pan J, Yu W, Lv J, Yan J, et al. Preoperative Controlling Nutritional Status (CONUT) score predicts short-term outcomes of patients with gastric cancer after laparoscopy-assisted radical gastrectomy. World J Surg Oncol. 2021;19(1):25. https://doi.org/10.1186/s12957-021-02132-6.

14. Lee CS, Won DD, Oh SN, Lee YS, Lee IK, Kim IH, et al. Prognostic role of presarcopenia and body composition with long-term outcomes in obstructive colorectal cancer: a retrospective cohort study. World J Surg Oncol. 2020; 18(1):230. https://doi.org/10.1186/s12957-020-02006-3.

15. Sakamoto T, Yagyu T, Uchinaka E, Miyatani K, Hanaki T, Kihara K, et al. Sarcopenia as a prognostic factor in patients with recurrent pancreatic cancer: a retrospective study. World J Surg Oncol. 2020;18(1):221. https://doi. org/10.1186/s12957-020-01981-X.

16. Maeda N, Shirakawa Y, Tanabe S, Sakurama K, Noma K, Fujiwara T. Skeletal muscle loss in the postoperative acute phase after esophageal cancer surgery as a new prognostic factor. World J Surg Oncol. 2020;18(1):143. https://doi.org/10.1186/s12957-020-01908-6.

17. Nakano $Y$, Hirata $Y$, Shimogawara $T$, Yamada $T$, Mihara $K$, Nishiyama $R$, et al. Frailty is a useful predictive marker of postoperative complications after pancreaticoduodenectomy. World J Surg Oncol. 2020;18(1):194. https://doi org/10.1186/s12957-020-01969-7.

18. Peixoto da Silva S, Santos JMO, Costa ESMP, Gil da Costa RM, Medeiros R. Cancer cachexia and its pathophysiology: links with sarcopenia, anorexia and asthenia. J Cachexia Sarcopenia Muscle. 2020;11:619-35.

19. Inaba S, Hinohara A, Tachibana M, Tsujikawa K, Fukada SI. Muscle regeneration is disrupted by cancer cachexia without loss of muscle stem cell potential. PLoS One. 2018;13(10):e0205467. https://doi.org/10.1371/ journal.pone.0205467.

20. Kanazawa Y, Yamada T, Kakinuma D, Matsuno K, Ando F, Fujita I, et al. Skeletal muscle mass depletion after gastrectomy negatively affects the prognosis of patients with gastric cancer. Anticancer Res. 2020;40(8):4271-9. https://doi.org/10.21873/anticanres.14429.

21. Yamazaki Y, Kanaji S, Takiguchi G, Urakawa N, Hasegawa H, Yamamoto M, et al. Skeletal muscle loss after laparoscopic gastrectomy assessed by measuring the total psoas area. Surg Today. 2020;50(7):693-702. https://doi. org/10.1007/s00595-019-01936-0.

22. Antoun S, Borget I, Lanoy E. Impact of sarcopenia on the prognosis and treatment toxicities in patients diagnosed with cancer. Curr Opin Support Palliat Care. 2013;7(4):383-9. https://doi.org/10.1097/SPC.0000000000000011.

23. Japanese Gastric Cancer Association: The Japanese Gastric Cancer Treatment Guidelines 2014 (version 4). Gastric Cancer. 2017;20(1):1-19. https://doi.org/10.1007/s10120-016-0622-4.

24. Harada K, Ida S, Baba Y, Ishimoto T, Kosumi K, Tokunaga R, et al. Prognostic and clinical impact of sarcopenia in esophageal squamous cell carcinoma. Dis Esophagus. 2016;29(6):627-33. https://doi.org/10.1111/dote.12381.

25. Mitsiopoulos N, Baumgartner RN, Heymsfield SB, Lyons W, Gallagher D, Ross $\mathrm{R}$. Cadaver validation of skeletal muscle measurement by magnetic resonance imaging and computerized tomography. J Appl Physiol (1985). 1998:85:115-22.

26. Shen W, Punyanitya M, Wang Z, Gallagher D, St-Onge MP, Albu J, et al. Total body skeletal muscle and adipose tissue volumes: estimation from a single abdominal cross-sectional image. J Appl Physiol (1985). 2004;97:2333-8.

27. Martin L, Birdsell L, Macdonald N, Reiman T, Clandinin MT, McCargar LJ, et al. Cancer cachexia in the age of obesity: skeletal muscle depletion is a powerful prognostic factor, independent of body mass index. J Clin Oncol. 2013;31(12):1539-47. https://doi.org/10.1200/JCO.2012.45.2722.

28. Japanese Gastric Cancer Association: The Japanese Gastric Cancer Treatment Guidelines 2010 (version 3). Gastric Cancer. 2011;14(2):113-23. https://doi.org/10.1007/s10120-011-0042-4.

29. Basch E, Reeve BB, Mitchell SA, Clauser SB, Minasian LM, Dueck AC, et al. Development of the National Cancer Institute's patient-reported outcomes version of the common terminology criteria for adverse events (PRO-CTCA E). J Natl Cancer Inst. 2014;106(9):dju244. https://doi.org/10.1093/jnci/dju244.

30. Prado CM, Baracos VE, McCargar LJ, Reiman T, Mourtzakis M, Tonkin K, et al. Sarcopenia as a determinant of chemotherapy toxicity and time to tumor progression in metastatic breast cancer patients receiving capecitabine treatment. Clin Cancer Res. 2009;15(8):2920-6. https://doi.org/10.1158/10780432.CCR-08-2242.

31. Shachar SS, Deal AM, Weinberg M, Nyrop KA, Williams GR, Nishijima TF, et al. Skeletal muscle measures as predictors of toxicity, hospitalization, and survival in patients with metastatic breast cancer receiving taxane-based chemotherapy. Clin Cancer Res. 2017:23(3):658-65. https://doi.org/10.1158/1 078-0432.CCR-16-0940.

32. Tan BH, Brammer K, Randhawa N, Welch NT, Parsons SL, James EJ, et al. Sarcopenia is associated with toxicity in patients undergoing neo-adjuvant chemotherapy for oesophago-gastric cancer. Eur J Surg Oncol. 2015;41(3): 333-8. https://doi.org/10.1016/j.ejso.2014.11.040

33. Nies AT, Magdy T, Schwab M, Zanger UM. Role of ABC transporters in fluoropyrimidine-based chemotherapy response. Adv Cancer Res. 2015;125: 217-43. https://doi.org/10.1016/bs.acr.2014.10.007.

34. Caudle KE, Thorn CF, Klein TE, Swen JJ, McLeod HL, Diasio RB, et al. Clinical pharmacogenetics implementation consortium guidelines for dihydropyrimidine dehydrogenase genotype and fluoropyrimidine dosing. Clin Pharmacol Ther. 2013;94(6):640-5. https://doi.org/10.1038/clpt.2013.172.

35. Gusella M, Toso S, Ferrazzi E, Ferrari M, Padrini R. Relationships between body composition parameters and fluorouracil pharmacokinetics. $\mathrm{Br}$ J Clin Pharmacol. 2002;54(2):131-9. https://doi.org/10.1046/j.1365-2125.2 002.01598.x

36. Voron $T$, Tselikas L, Pietrasz D, Pigneur F, Laurent A, Compagnon $\mathrm{P}$, et al. Sarcopenia impacts on short- and long-term results of hepatectomy for 
hepatocellular carcinoma. Ann Surg. 2015;261(6):1173-83. https://doi.org/1 0.1097/SLA.0000000000000743.

37. Lee JS, Kim YS, Kim EY, Jin W. Prognostic significance of CT-determined sarcopenia in patients with advanced gastric cancer. PLoS One. 2018;13(8): e0202700. https://doi.org/10.1371/journal.pone.0202700.

38. Takahari D. Second-line chemotherapy for patients with advanced gastric cancer. Gastric Cancer. 2017;20(3):395-406. https://doi.org/10.1007/s10120017-0707-8.

39. Hironaka S, Ueda S, Yasui H, Nishina T, Tsuda M, Tsumura T, et al. Randomized, open-label, phase III study comparing irinotecan with paclitaxel in patients with advanced gastric cancer without severe peritoneal metastasis after failure of prior combination chemotherapy using fluoropyrimidine plus platinum: WJOG 4007 trial. J Clin Oncol. 2013;31(35): 4438-44. https://doi.org/10.1200/JCO.2012.48.5805.

40. Ford HE, Marshall A, Bridgewater JA, Janowitz T, Coxon FY, Wadsley J, et al. Docetaxel versus active symptom control for refractory oesophagogastric adenocarcinoma (COUGAR-02): an open-label, phase 3 randomised controlled trial. Lancet Oncol. 2014;15(1):78-86. https://doi.org/10.1016/S14 70-2045(13)70549-7.

41. Japanese Gastric Cancer Association: The Japanese Gastric Cancer Treatment Guidelines 2018 (version 5). Gastric Cancer. 2017;24:1-21. https:// doi.org/10.1007/s10120-020-01042-y.

42. Yamamoto K, Nagatsuma Y, Fukuda Y, Hirao M, Nishikawa K, Miyamoto A, et al. Effectiveness of a preoperative exercise and nutritional support program for elderly sarcopenic patients with gastric cancer. Gastric Cancer. 2017:20(5):913-8. https://doi.org/10.1007/s10120-016-0683-4.

43. Kimura Y, Nishikawa K, Kishi K, Inoue K, Matsuyama J, Akamaru Y, et al. Long-term effects of an oral elemental nutritional supplement on postgastrectomy body weight loss in gastric cancer patients (KSESO02). Ann Gastroenterol Surg. 2019;3(6):648-56. https://doi.org/10.1002/ags3.12290.

\section{Publisher's Note}

Springer Nature remains neutral with regard to jurisdictional claims in published maps and institutional affiliations.

Ready to submit your research? Choose BMC and benefit from:

- fast, convenient online submission

- thorough peer review by experienced researchers in your field

- rapid publication on acceptance

- support for research data, including large and complex data types

- gold Open Access which fosters wider collaboration and increased citations

- maximum visibility for your research: over $100 \mathrm{M}$ website views per year

At $\mathrm{BMC}$, research is always in progress.

Learn more biomedcentral.com/submissions 